\title{
CORRECTION
}

\section{Correction to: Real-World Trends in Characteristics of Patients with Migraine Newly Initiated on Erenumab in the USA: A Retrospective Analysis}

Juanzhi Fang (i) - Stephanie Korrer · Jonathan C. Johnson •

Mark A. Cheadle · Roshani Shah · Matias L. Ferraris · Cristina Lopez-Lopez

Published online: July 17, 2021

(C) Springer Healthcare Ltd., part of Springer Nature 2021

Correction to: Adv Ther (2021) 38:2921-2934

https://doi.org/10.1007/s12325-021-01677-y

There are few corrections in the original publication.

In the Fig. 1 the word "Date" under the demographics heading need to be deleted.

In the Fig. 6a: In Y-axis correct the spelling proprtion to Proportion. In the Fig. 6b: change Y-axis title to Proportion of patients (\%).

The original article can be found online at https://doi. org/10.1007/s12325-021-01677-y.

J. Fang $(\varangle) \cdot$ M. A. Cheadle · R. Shah

Novartis Pharmaceuticals Corporation, East

Hanover, NJ, USA

e-mail: jenny.fang@novartis.com

S. Korrer · J. C. Johnson

Optum, Eden Prairie, MN, USA

M. L. Ferraris C. Lopez-Lopez

Novartis Pharma AG, Basel, Switzerland 